
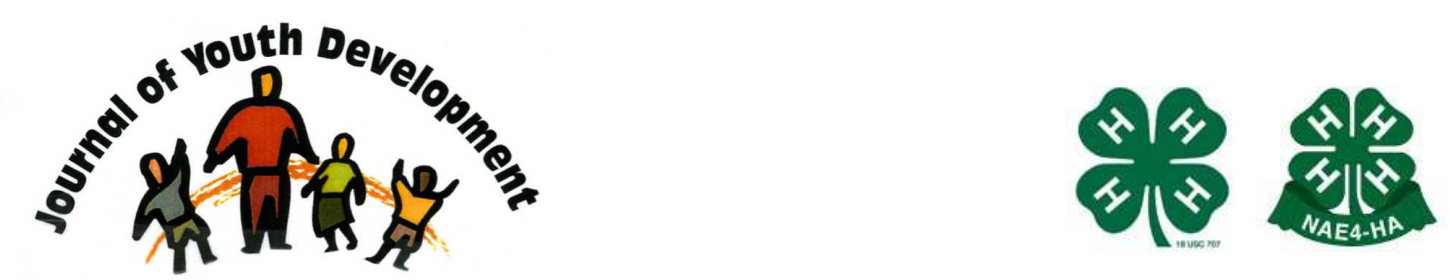

Bridging Research \& Practice

\title{
"Coaching the Camp Coach: \\ Leadership Development for Small Organizations" \\ Resource Review
}

\author{
Jason Hedrick \\ OSU Extension \\ The Ohio State University \\ Ottawa, Ohio \\ hedrick.10@cfaes.osu.edu
}

Greg Homan

Wright State University Lake Campus

Celina, Ohio

greg.homan@wright.edu 


\title{
JOURNAL OF YOUTH DEVELOPMENT \\ bridging research and practice

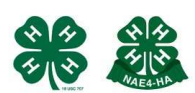

Volume 4, Number 3, Fall 2009

Article 090403RR001

\section{"Coaching the Camp Coach: Leadership Development for Small Organizations" Resource Review}

\author{
Jason Hedrick \\ The Ohio State University \\ Greg Homan \\ Wright State University Lake Campus
}

\begin{abstract}
Coaching is an important component of successful professional growth for leaders within any organization. However, organizations with limited resources may have challenges providing such coaching opportunities. This can be especially true for small business, non profit organizations and summer camps. "Coaching the Camp Coach; Leadership Development for Small Organizations" by Shelton, M. (2003) provides a framework, both in theory and practice, for camp leaders to improve interpersonal and intrapersonal skills through self evaluation. Accompanying the book is a CD-ROM that has multiple worksheets to be used in conjunction with the text.
\end{abstract}

\section{Introduction}

Camp organizations are no different than large corporate business in the fact that their success depends on performance driven leaders. Camps often utilize a young workforce to execute important elements of a camping program and this group often times is underserved in terms of leadership development (Shelton, 2003). The expensive executive coach used by big business is not realistic for youth camps with limited resources. Despite having limited resources, it is imperative for camp directors to seek ongoing training to become better leaders.

"Coaching the Camp Coach; Leadership Development for Small Organizations" by Shelton, M. (2003) is a cost effective means to camp leadership training. Not only can the text be used by camp directors to improve upon their own leadership skills, but it can also be implemented into staff trainings for all levels within a camp organization. The author notes the text is not designed to be a substitute for organizations that can provide trained coaches to their 
employees. It is intended to be a cost efficient solution for those who cannot afford executive coaches (Shelton, 2003).

\section{Content \\ - Leadership \\ - The Basic Four \\ - Physical Capacity \\ - Emotional Capacity \\ - Mental Capacity \\ - Integrative Factors \\ - Personal Change \\ - Coaching and Training}

\section{Application}

This text is a valuable foundation for anyone working in a leadership position, particularly for camp organizations. The author takes great care in defining leadership positions and differentiating them from managers. Each role is distinctly different. The introduction of the book outlines theoretical models of high performing leaders and identifies the various roles of leaders within camp organizations. These roles are first defined and then expanded upon using situational examples that are camp specific. The author provides a valuable perspective and analysis of leadership development with real-world examples throughout the text.

The author challenges the reader to not only evaluate their existing leadership skills, but also reflect on their strengths and weaknesses as a leader. The initial chapter focuses on what the author terms the "Basic Four." These "Basic Four" internal reactions include thoughts, feelings, sensations, and impulses. They guide an individual's external behavior. According to the author, a purposeful increase in monitoring these internal events will result in more self control and better leadership (Shelton, 2003).

Throughout the text there are integrated worksheets (found on the accompanying CD-ROM) that allow the reader to self-reflect on their leadership skills. References to the appropriate worksheets are found within the chapters and relate to the leadership topic being discussed. Beyond using the text to sharpen your own leadership skills, it can be adapted for camp staff training in the hopes of increasing the effectiveness of the entire camp team. This resource can be found at the American Camp Association online bookstore (www.cart-acabookstore.com) for $\$ 32.95$.

\section{Reference}

Shelton, M. (2003). Coaching the Camp Coach; Leadership Development for Small Organizations, Martinsville, Indiana: American Camping Association.

(C) Copyright of Journal of Youth Development Bridging Research and Practice. Content may not be copied or emailed to multiple sites or posted to a listserv without copyright holder's express written permission. However, users may print, download or email articles for individual use. 